\title{
Cross-Shore Transport Feature for GenCade
}

\section{US Army Corps of Engineers}

by Yan Ding, Richard Styles, Sung-Chan Kim, Rusty Permenter, and Ashley Frey

PURPOSE: The purpose of this Coastal and Hydraulics Engineering Technical Note (CHETN) is to introduce a new cross-shore transport capability in GenCade. The cross-shore transport feature is based on a new empirical algorithm that includes wave velocity skewness to calculate the near-bed sediment flux. Validation of the new algorithm was achieved using shoreline position data collected at the US Army Corps of Engineers (USACE) Field Research Facility (FRF) located in Duck, NC. This CHETN presents the theory behind the new cross-shore transport feature and validation using data collected at the FRF. Comparisons with and without the cross-shore feature are presented to demonstrate the improved GenCade performance. The CHETN concludes information that should be considered when using this new feature.

INTRODUCTION: GenCade is a one-line shoreline evolution model that uses an alongshore sediment transport model driven by incident waves (Frey et al. 2012). Mechanical shoreline movement is predominantly driven by gradients in the alongshore transport and from independently specified sediment sources (e.g., due to beachfill) or sinks. Shoreline position is thus determined by the principle of mass conservation within a control volume, including the sediment sources and the balance of alongshore sediment fluxes through the updrift and downdrift boundaries. GenCade can estimate changes in sediment transport from shoreline anomalies (e.g., structures, inlets) that alter alongshore fluxes. Note that GenCade can compute shoreline retreat based on changes in sea level elevation and land subsidence. However, these processes are driven by large-scale climate and geophysical variability and are assumed to be independent of the local sediment transport processes.

Previous versions of GenCade do not consider cross-shore transport (a shore-normal sediment flux), which can introduce sediment from nearshore sources. Shoreline erosion and accretion are affected by both longshore and cross-shore transport. Storms normally cause beach erosion and shift the mean shoreline position landward (e.g., Thornton et al. 1996; Komar 1998). They may also induce more cross-shore transport than longshore transport. During a fair-weather (non-storm) condition, wave shoaling and asymmetry in the nearshore can drive onshore transport, thereby building the beach and moving the shoreline seaward (e.g., Elgar et al. 2001). Therefore, adding the features to account for shore-normal sediment flux will improve simulation of shoreline evolution in regions with significant cross-shore transport. GenCade has been modified accordingly to incorporate cross-shore transport as an important factor to estimate the shoreline change. This CHETN presents the mathematical formulations for calculation of cross-shore sediment flux and preliminary validation results of GenCade with this new capability by simulating shoreline changes in the FRF coast, Duck, NC.

BACKGROUND: Shoreline change in the present GenCade model is calculated by using the equation of mass conservation with longshore sediment transport in a control volume. By including 
the shoreline changes due to cross-shore transport, sea level rise, and land subsidence, the shoreline evolution equation in GenCade can be written as (Frey et al. 2012; Ding et al. 2018):

$$
\frac{\partial y}{\partial t}=\frac{1}{D_{S}}\left(-\frac{\partial Q_{l}}{\partial x}+q_{s}+\phi\right)-\frac{R+S}{\tan \beta}
$$

where $y=$ cross-shore coordinate and represents the shoreline position, $t=$ time, $x=$ the alongshore coordinate, $Q_{l}=$ longshore transport rate, $D_{s}=$ total closure depth, $q_{s}=$ line source or sink of sediment, $\phi=$ cross-shore transport rate (positive sign for onshore transport, negative for offshore), $R=$ sea level rise rate, $S=$ subsidence, $\tan \beta=$ an average beach slope $\left(=D_{s} / W_{*}, W_{*}=\right.$ width of the active profile (approximately the width of longshore sediment transport zone). Equation (1) represents a new governing equation for GenCade to simulate shoreline evolution driven by longand cross-shore transport, sea level change, and land subsidence. The shoreline retreat rate due to sea level rise and subsidence is based on the assumption of equilibrium beach profile (Bruun 1962; Rosati et al. 2013). For longshore transport, the Coastal Engineering Research Center (CERC) formula (Frey et al. 2012) is still used to estimate $Q_{l}$.

Cross-shore sediment transport plays an important role in driving beach evolution including shoreline movement and bar migration. Observation of nearshore morphological changes has shown that cross-shore transport induced by nearshore wave dynamics results in onshore and offshore sandy bar migration (e.g., Elgar et al. 2001). During storms, strong waves drive intense offshore-directed flow (undertow) that moves bars toward offshore (Thornton et al. 1996; Gallagher et al. 1998; Kuriyama and Nakatsukasa 2000), as well as erosion of berm and dune due to overwash and overtopping (Kobayashi et al. 2009, 2010). Under fair-weather (no storm) conditions, near-bed wave orbital motion is dominant in the nearshore zone and induces net onshore sediment transport over a wave period. Long-term low energetic wave action is a predominant driving force for onshore bar migration. Simulation of bar migration is a key task for prediction of nearshore morphological changes driven by wave and current, but it is still not successful due to lack of knowledge on mechanism of massive sediment motions. Empirical parametric formulations for estimating cross-shore sediment transport flux have been built up based on analytical models and laboratory and field observation datasets. Early versions of those formulations, which are based on phase-averaged bottom shear stresses, were not successful for simulating bar migration (Elgar et al. 2001). Recent development of cross-shore sediment transport models suggests inclusion of nonlinearity of wave dynamics in the nearshore such as skewness of particle velocity and acceleration is indispensable to simulation onshore bar migration (Hoefel and Elgar 2003; Hsu et al. 2006; Fernández-Mora et al. 2015).

Progress in development of short- and mid-term beach profile evolution models has been made by solely considering cross-shore sediment transport. Theories for estimation of beach evolution and cross-shore transport are beneficial to improving long-term shoreline evolution models such as GenCade. Most beach profile models solve a one-dimensional (1-D) time-dependent (or phaseresolving) morphological change equation based on the mass conservation of cross-shore sediment transport driven by waves and currents (e.g., Larson and Kraus 1989; Hsu et al. 2006; Kobayashi et al. 2008; Johnson et al. 2012; Fernández-Mora et al. 2015). For calculation of cross-shore sediment transport, Hsu et al. (2006) used a modified energetics-type model that separates transport associated only with wave orbital velocities from transport associated with the mean 
current (including interaction with the oscillatory current). Particle velocity is computed by a phase-resolving boundary layer model, which enables the beach profile evolution model to resolve nonlinear boundary layer processes. Simulated beach profiles over a 5-day period near Duck, NC, USA, reproduced the sandbar migration. Fernández-Mora et al. (2015) considered the extended energetic model of Hsu et al. (2006) and the intra-wave parameterization of Ruessink et al. (2012) to model bar migrations during 72 days at Duck, NC. They concluded that accounting for the joint action of both velocity and acceleration skewnesses results in major improvements in the modeled onshore bar migration and is essential to accurately model the evolution of the entire cross-shore bottom profile.

Kobayashi et al. (2008) developed a phase-averaged sediment transport model to predict the timeaveraged rates of cross-shore suspended sand and bed load transport, in which the nonlinear effect was simulated by phase-averaged wave and flow models. By extending the model of Kobayashi et al. (2008), Johnson et al. (2012) developed a cross-shore numerical model, CSHORE, for engineering applications for simulating beach profile evolution driven by waves and currents.

Thus, for simulation of shoreline evolution driven by cross-shore sediment transport, one may employ a cross-shore beach profile model as mentioned above to directly obtain shoreline positions varying with the beach profiles. However, this approach will be time-consuming for long-term (decades-long) shoreline evolution simulation and may not be accurate if longshore sediment transport is excluded. Therefore, to preserve the feature of long-term computational efficiency of GenCade and its capability of the longshore sediment transport process, a new empirical parametric formulation is proposed for estimating the net cross-shore sediment transport rate, which contributes to shoreline evolution. Based on the beach profile model of Fernández-Mora et al. (2015), by taking into account three parts of cross-shore sediment transport driven by particle velocity, current, and gravity (i.e., slope effect), the wave-average net cross-shore sediment transport rate $(\phi)$ at a cross-shore section is determined as follows:

$$
\phi=\frac{\alpha_{D}}{1-p}\left(Q_{w}+Q_{c}+Q_{D}\right)
$$

where $p=$ sand porosity, $Q_{w}$ and $Q_{c}=$ net sediment transport due to waves and currents, respectively, $Q_{D}=$ diffusive transport resulting from the tendency of sand to move downslope, and $\alpha_{D}=$ a scaling parameter calibrated by observation data. Net sediment transport for the wave and current are written as follows (Hsu et al. 2006):

$$
Q_{w}=\frac{C_{W}}{(s-1) g}\left(\frac{\varepsilon_{B}}{\tan \varphi}<\left|\vec{U}_{0}\right|^{2} U_{0, y}>+\frac{\varepsilon_{S}}{W_{0}}<\left|\vec{U}_{0}\right|^{3} U_{0, y}>\right)
$$

and

$$
Q_{c}=\frac{C_{C}}{(s-1) g}\left(\frac{\varepsilon_{B}}{\tan \varphi}<\left|\vec{U}_{t}\right|^{2} U_{y}>+\frac{\varepsilon_{S}}{W_{0}}<\left|\vec{U}_{t}\right|^{3} U_{y}>\right)
$$


where $C_{w}, C_{c}, \varepsilon_{B}$, and $\varepsilon_{S}$ are empirical coefficients, $\vec{U}_{0}=$ near-bed wave orbital velocity vector $(y$ denotes the cross-shore component), $\vec{U}_{t}=$ total velocity vector (near-bed wave orbital velocity plus currents), $U_{y}=$ mean velocity in the cross-shore direction including the offshore-directed undertow velocity, $\varphi=$ friction angle, $W_{0}=$ sediment fall velocity, $s=$ relative sediment density $\left(=\rho_{s} / \rho\right), \mathrm{g}$ $=$ acceleration due to gravity, $\rho_{s}=$ sediment density, and $\rho=$ fluid density. The brackets $<>$ denote a wave average, and || denotes the absolute value. The diffusive transport term is written as

$$
Q_{D}=\frac{\lambda_{d} v \tan \beta}{\tan \varphi(\tan \varphi-\tan \beta)}
$$

where $\lambda_{d}$ and $v$ are empirical coefficients. Details on the theory of the three terms, including representative values for the empirical coefficients, can be found in Hsu et al (2006) and Fernández-Mora et al. (2015). The contribution from wave asymmetry and velocity skewness is estimated by the free-stream near-bed horizontal orbital velocity formula $\tilde{U}_{0}(t)$ proposed by Abreu et al. (2010), i.e.,

$$
\tilde{U}_{0}(t)=U_{w} f \frac{\sin (\omega t)+\frac{r \sin \varphi_{w}}{1+\sqrt{1-r^{2}}}}{1-r \cos \left(\omega t+\varphi_{w}\right)}
$$

Here, $\mathrm{t}=$ time, $U_{w}=$ the bottom orbital velocity given by linear wave theory (for symmetrical wave shape), $\omega=$ angular frequency, $\varphi_{w}=$ phase, $r$ is a non-linearity measure, and $f=\sqrt{1-r^{2}}$ is a nondimensional factor. For $r=0$, Equation (6) describes sinusoidal flow. For $0<r<1$, it results in velocity-asymmetric flow for $\varphi_{w}=0$, velocity-skewed flow for $\varphi_{w}=-\pi / 2$, and mixed asymmetric-skewed flow for $-\pi / 2<\varphi_{w}<0$. To estimate the parameter values of $r$ and $\varphi_{w}$, Malarkey and Davies (2012) and Ruessink et al. (2012) have developed a regression relationship with wave skewness and asymmetry based on multiple observation data samples. Ruessink et al. (2012) selected the Ursell number as the single dependent parameter to develop the regression equation for the data samples. For the details of calculation procedure, one may refer to Ruessink et al. (2012) and Malarkey and Davies (2012). Recently, Rocha et al. (2017) proposed another approach to estimate $r$ and $\varphi_{w}$ by relating to wave steepness, spectral bandwidth, beach slope, as well as the Ursell number. For simplicity, the approach of Ruessink et al. (2012) is used to estimate wave skewness and asymmetry, which is related to the Ursell number only. By including mean currents, the total near-bed orbital velocity vector $\vec{U}_{0}$ is calculated as follows:

$$
\vec{U}_{0}(t)=\left(U_{\text {undertow }}+\tilde{U}_{0}(t) \cos \theta\right) \vec{i}+\left(U_{\text {alongshore }}+\tilde{U}_{0}(t) \cos \theta\right) \vec{j}
$$

where $\theta$ is the wave direction, $\vec{i}$ is the cross-shore unit direction vector, $\vec{j}$ is the alongshore unit direction vector, $U_{\text {undertow }}$ is the undertow velocity in the cross-shore direction, $U_{\text {alongshore }}$ is the alongshore mean current velocity. The undertow velocity is estimated from the mass fluxes due to 
waves and rollers proposed by Kuriyama and Nakatsukasa (2010). To simplify calculations, only the net cross-shore sediment rate at breaking is used for the cross-shore transport in Equation (2). The parameter $\alpha_{D}$ will be calibrated.

By using Eq. (6), Figure 1 plots the time histories of the near-bed orbital velocities for a wave at water depths of $0.5,0.8,2.0$, and $5.0 \mathrm{~m}^{1}$ if shoaling effect is neglected. It shows a more symmetric wave at $5.0 \mathrm{~m}$ water depth and becomes more skewed in shallower water. The velocity amplitude is skewed such that the maximum velocity during the forward half of the wave cycle is greater than the amplitude during the reverse half of the wave cycle.

With the calibrated parameter $\alpha_{D}, C_{w}, C_{c}, \varepsilon_{B}$, and $\varepsilon_{S}$ in the sediment transport equations, calculation of the cross-shore transport rate $(\phi)$ is dependent on the breaking wave calculated in GenCade. Because the new algorithm does not require a two-dimensional grid, the basic GenCade computational scheme is unaltered, while incorporating new physics to represent a key sediment source that can affect shoreline position.

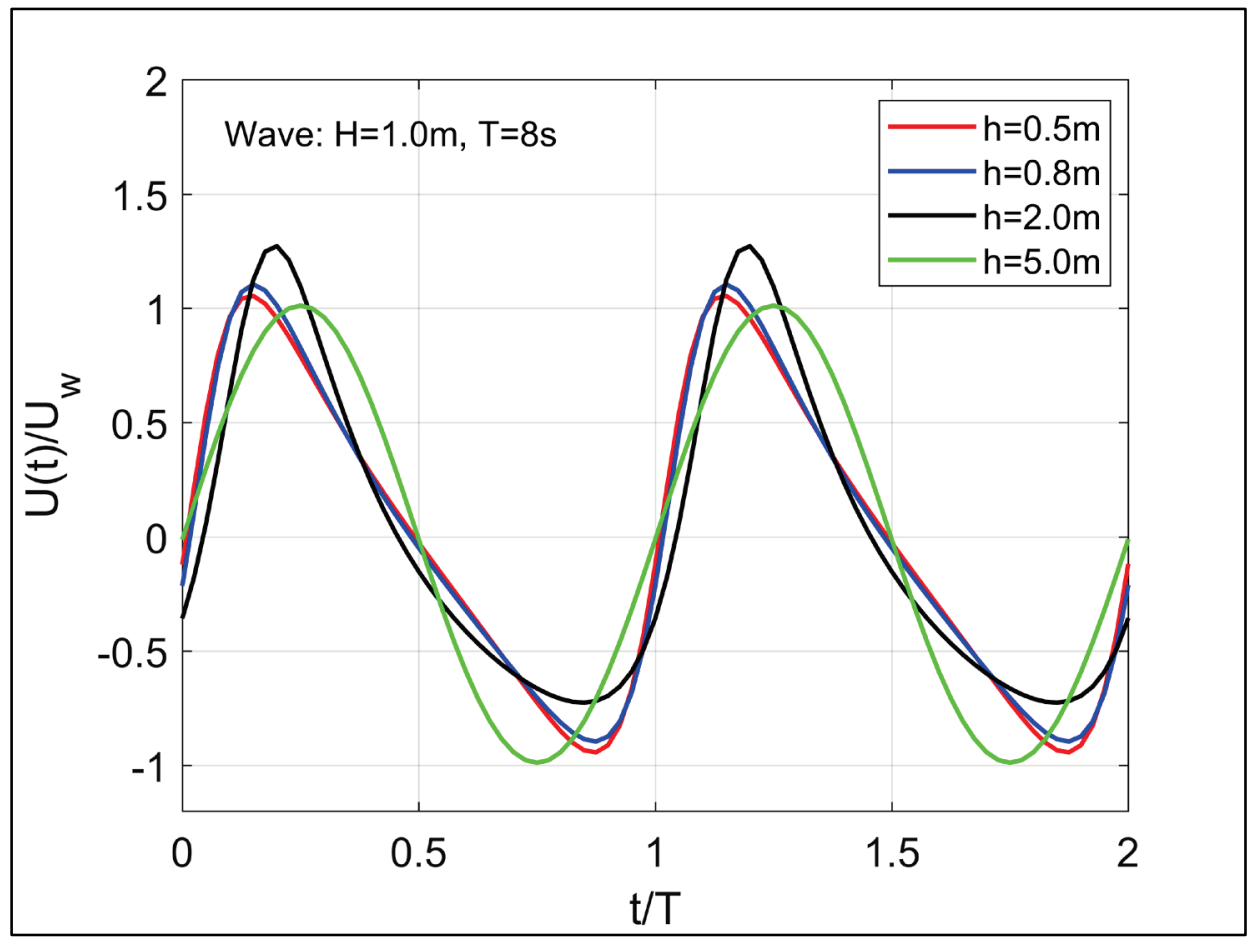

Figure 1. Near-bed orbital velocities for a wave (height $H=1.0 \mathrm{~m}$ and period $T=8 \mathrm{~s}$ ) at four water depths. The positive sign denotes onshore direction.

Shoreline position data. The USACE FRF has surveyed beach profile data since the 1970s. The temporal and spatial coverage has varied through time. New surveys are presently collected approximately every month and after major storms. The cross-shore profiles extend from the dunes to $950 \mathrm{~m}$ offshore and the alongshore transects cover the length of the FRF property $(1000 \mathrm{~m})$ centered on the pier (Figure 2). Depending upon the year, the surveys were taken from either the

\footnotetext{
${ }^{1}$ For a full list of the spelled-out forms of the units of measure used in this document, please refer to US Government Publishing Office Style Manual, 31st ed. (Washington, DC: US Government Publishing Office, 2016), 248-52, https://www.govinfo.gov/content/pkg/GPO-STYLEMANUAL-2016/pdf/GPO-STYLEMANUAL-2016.pdf.
} 
Coastal Research Amphibious Buggy (CRAB) or the Lighter Amphibious Resupply Cargo (LARC). The FRF reports (Forte et al. 2017) that the vertical accuracy is 2 to $3 \mathrm{~cm}$, and all data are referenced to NAVD88. The bathymetric contours are generally shore parallel and indicate a gently sloping beach and a well-defined offshore bar. The bathymetry is noticeably affected by the presence of the pier, which reveals increased scour around the pilings (Figure 2b). Model validation is conducted using data collected between 1999 and 2005. This period has consistent temporal coverage and is also chosen as the calibration subset of the longer time series. In this way, new features can be tested using this base dataset. More validation can be conducted independently outside this timeframe. During October 1999 to October 2005, a total of 38 LARC shoreline surveys were carried out, and 863 valid shoreline position measurements in a maximum of 46 individual beach profiles (transects) were recorded. Shoreline position was determined by interpolating to the zero-depth point of each profile relative to mean water level.

Wave data were obtained from the $8 \mathrm{~m}$ array located on the $8 \mathrm{~m}$ contour approximately $900 \mathrm{~m}$ from shore $\left(36^{\circ} 1114.06 \mathrm{~N} 75^{\circ} 4434.39 \mathrm{~W}\right)$ (FRF 2019). The array has been recording wave information since 1987 and reports spectral wave distribution every hour, which is converted to significant wave height, wave period, and direction as input to GenCade.

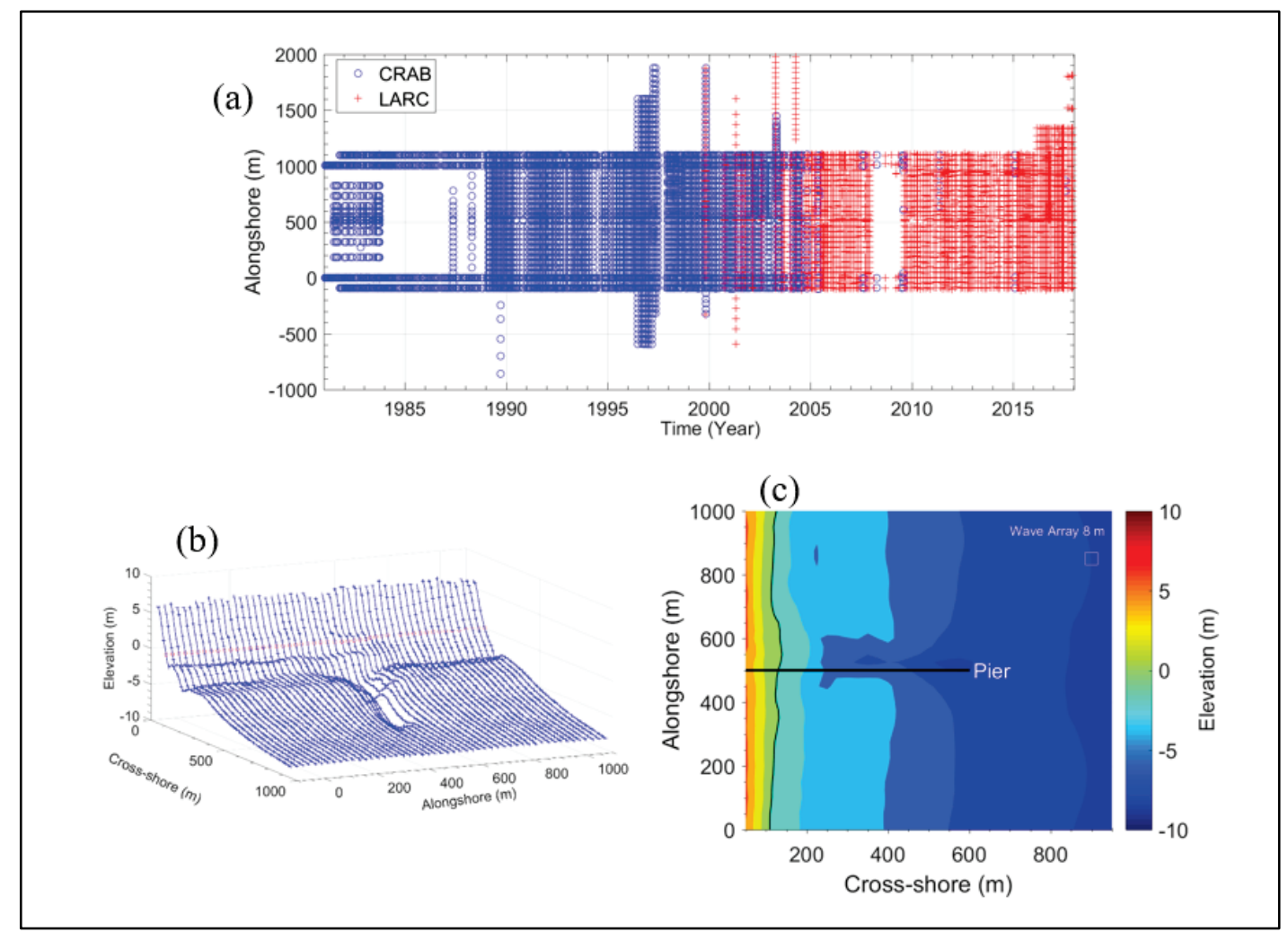

Figure 2. (a) Beach profile locations dating back to 1985 illustrating the cross-shore and temporal coverage. (b) Representative beach profile coverage area along the FRF property (07/24/1996). Red circles denote the interpolated shoreline position. The trough in the middle of the map identifies the location of the pier (Figure 3). (c) Bathymetric contour plot showing the relatively straight and parallel contours except in the vicinity of the pier (07/24/1996). The block line is the extracted shoreline. 
GenCade setup. To validate the GenCade model, shoreline evolution for 6 years from $10 / 23 / 1999$ to $10 / 23 / 2005$ was simulated. The simulated coastline is $5.1 \mathrm{~km}$ long centered on the FRF pier (Figure 3). The wave data observed at the $8 \mathrm{~m}$ array are used as the input to GenCade. Based on the analysis of FRF transect survey data between 1999 and 2006, it was found that the sediment closure depth is approximately $7.0 \mathrm{~m}$, and the berm crest elevation is assumed to be 1.0 $\mathrm{m}\left(D_{s}=8 \mathrm{~m}\right)$. Gallagher et al. (1998) and Elgar et al. (2001) reported that the observations of sediment properties (i.e., DUCK94, Birkemeier et al. 1994) were made along a cross-shore transect extending from near the shoreline (mean sediment grain size $\approx 0.30 \mathrm{~mm}$ ) to approximately $4 \mathrm{~m}$ water depth (grain size $\approx 0.15 \mathrm{~mm}$ ). Therefore, the sediment grain size for calculating sediment transport rate in GenCade was set to $0.2 \mathrm{~mm}$, an average value in a cross-shore profile. The settling velocity $\left(W_{0}\right)$ of $2.5 \mathrm{~cm} / \mathrm{s}$ for this grain size is given by Hsu et al. (2006), which influences the estimations of cross-shore sediment transport calculated by Equations (3) and (4).

The 1-D computational grid size of the GenCade model is $20 \mathrm{~m}$. For the boundary conditions at the two ends of the domain, it is assumed that the gradient of longshore sediment transport is zero, which means a zero-divergence of $Q_{l}$ at the two ends is unable to change shoreline position, but the estimated cross-shore sediment transport $(\phi)$ by Equation (2) can still move the shoreline. Thus, to set up a zero-divergence longshore sediment transport, the "pinned" boundary condition (Frey et al. 2012) was specified for the GenCade model at the north and south boundaries, which are out of Figure 3.

The two empirical parameters in the CERC longshore sediment transport formulation, $K_{1}$ and $K_{2}$, were carefully calibrated. Through trial and error, two calibrated values of 0.40 and 0.25 for the two parameters respectively were found to provide the minimum root-mean-square error (RMSE) evaluated at all the 24 survey transects. The FRF pier is permeable to allow longshore sediment to pass underneath the pier. GenCade considers the effect of sediment bypassing through a groin, given a permeability factor to estimate sediment bypassing rate (Frey et al. 2012). The permeability factor of the pier is also a calibrated parameter. It was found that 0.6 is a reasonable value to represent the sand bypass process through the pier.

The values of empirical coefficients $C_{w}, C_{c}, \varepsilon_{B}$, and $\varepsilon_{C}$ in the cross-shore sediment transport equations (3) and (4) calibrated by Fernández-Mora et al. (2015) are directly used for calculating cross-shore sediment transport rate, as the values were calibrated by simulating beach profile changes using DUCK94 data. Using the sea level trend data at Duck, NC, published by the National Oceanic and Atmospheric Administration (NOAA), the relative sea level rise rate $(R+S)$ is set to $4.55 \mathrm{~mm} /$ year. For more discussion on effect of sea level change on shoreline retreat, one may refer to Ding et al. (2018). Finally, by trial and error for parameter calibration, the best value of the scaling parameter $\alpha_{D}$ in Equation (2) was found to be 1.50 . 


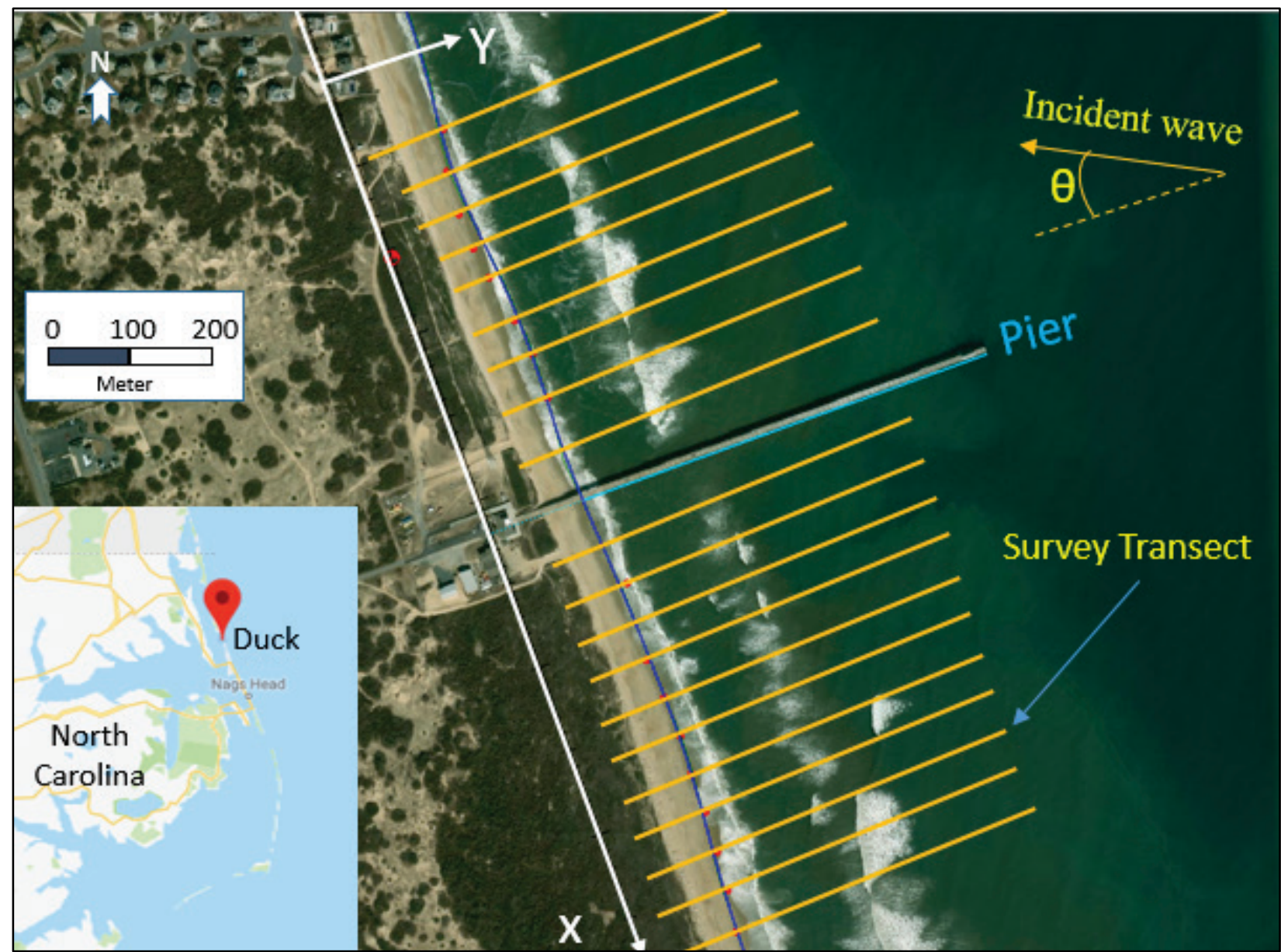

Figure 3. Study site in FRF, Duck, NC, and a close-up view of the GenCade computational domain. The 1-D gridline (i.e., $y(x)=0$ ) denotes the baseline (x-axis) of GenCade. The blue line is the initial shoreline measured on October 23, 1999. The yellow lines are survey transects.

MODEL AND DATA COMPARISONS: The wave measurements at the $8 \mathrm{~m}$ array during the 6-year study period (1999-2005) include a blend of low-energy periods and energetic storm conditions (Figure 4). Wave direction is relative to the shore normal with positive values denoting waves propagating from the north and northeast and negative values denoting waves propagating from the south or southeast. Over the size-year wave data, the mean wave height is approximately $1.0 \mathrm{~m}$, the mean direction is $5.0 \mathrm{deg}$ toward north, and the average period is approximately $9.0 \mathrm{~s}$. The majority of incident waves are within \pm 20 deg of shore normal. Table 1 lists corresponding wave statistics from the 6-year dataset. 

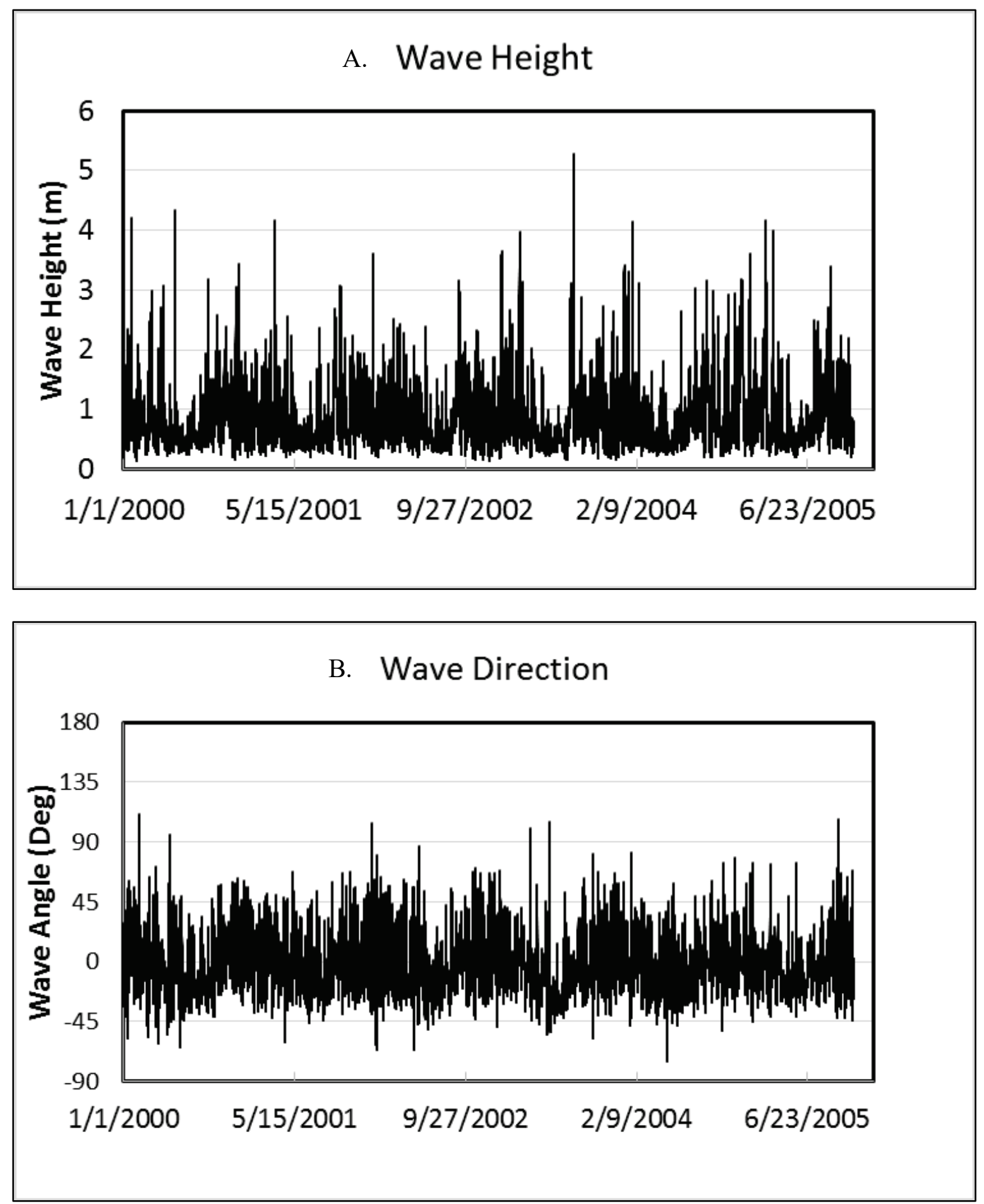

Figure 4. (A) Wave height and (B) wave direction relative to the shore normal during the simulation period. Zero deg denotes shore normal waves, and positive angles denote waves incident from the north or northeast. 


\begin{tabular}{|c|c|c|c|c|}
\hline \multicolumn{5}{|c|}{$\begin{array}{l}\text { Table 1. Wave statistics for the simulation timeframe } \\
\text { including the mean, minimum, maximum and standard } \\
\text { deviation. }\end{array}$} \\
\hline & Mean & Min & Max & STD \\
\hline $\mathrm{H}(\mathrm{m})$ & 0.82 & 0.14 & 5.28 & 0.53 \\
\hline $\mathrm{T}(\mathrm{s})$ & 9.18 & 3.09 & 18.96 & 2.68 \\
\hline Angle (deg) & -5.06 & -74.62 & 111.32 & 18.52 \\
\hline
\end{tabular}

Figure 5 shows model results of the cross-shore transport (blue line) with a high degree of variability, similar to the wave measurements. History of significant wave heights (orange line) at offshore is also plotted in the figure. The onshore transport (positive value) is mostly generated by small waves during fair weather conditions. The offshore transport (negative value) is associated with large waves during storms. The average transport rate (approximately $35 \mathrm{~m}^{3} / \mathrm{m}$ per year) indicates a net onshore movement at the FRF. Therefore, wave conditions during the simulation period tend to supply sediment to the beach while longshore transport will redistribute sediment along the shoreline.

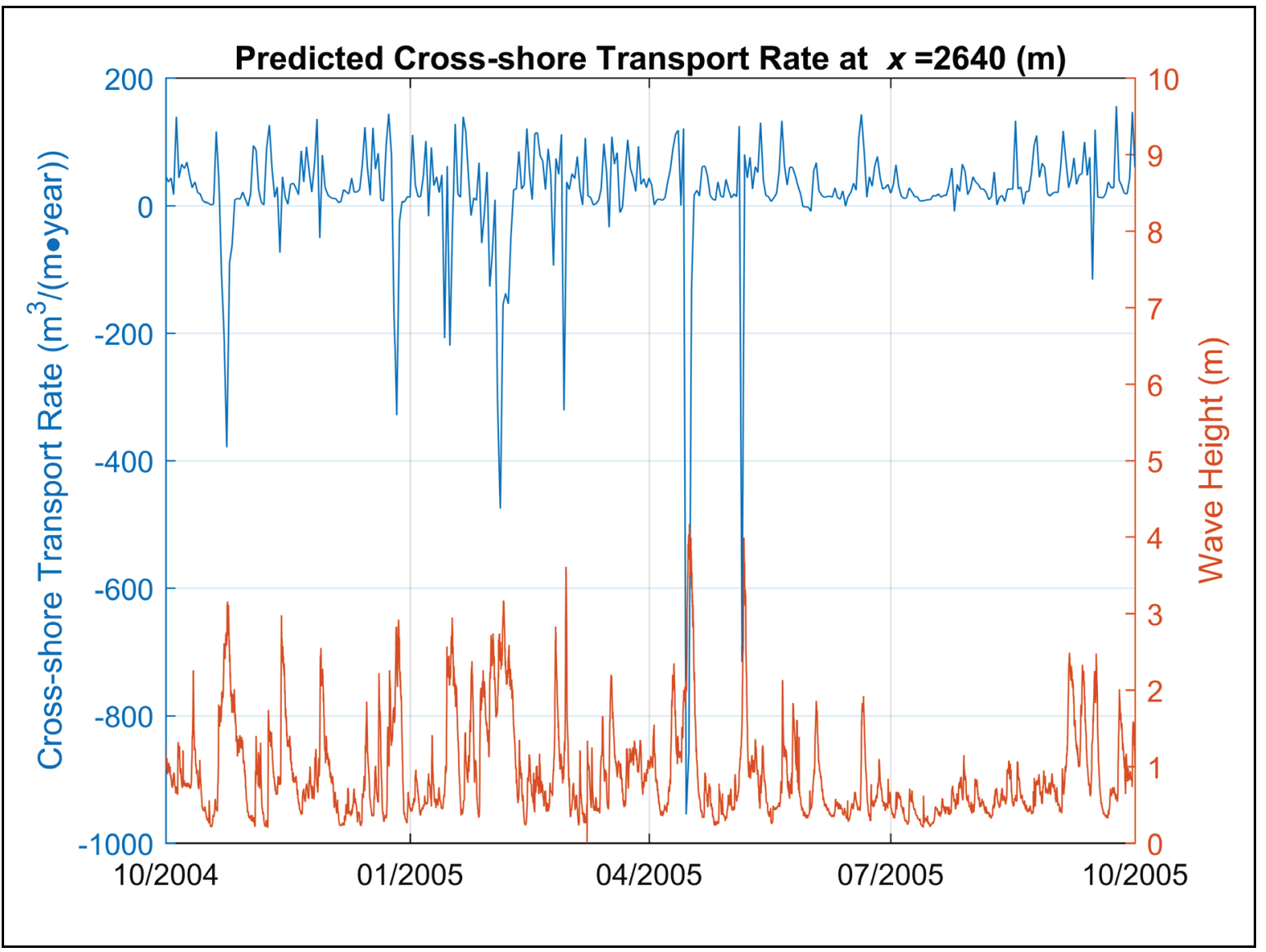

Figure 5. Time series of cross-shore sand transport rate at $x=2640 \mathrm{~m}$ (close to the pier) and wave heights at offshore. 
GenCade predictions. Model simulations with cross-shore sediment transport show better agreement with the measured shoreline position than those without (alongshore transport only) (Figure 6). To illustrate the model trends along the coast, the $x$-axis extends approximately $1 \mathrm{~km}$ north and south of the FRF property. Model predictions without cross-shore transport show a net shoreline retreat of approximately $20 \mathrm{~m}$ at all locations at the end of simulation (after 6 years). When cross-shore transport is included, the modeled shoreline in the vicinity of and south of the pier compares well with the measurements. North of the pier, the model shows a net retreat of approximately $10 \mathrm{~m}$. In general, the measured shoreline change shows variability in the alongshore direction, but the mean position does not change significantly. There is also evidence that the shoreline position is affected by the presence of the pier, with the shoreline shifting seaward south of the pier and landward north of the pier. This effect is clearly illustrated in Figure 6C, where the predicted shoreline is shifted seaward (landward) south (north) of the pier. The results can be interpreted as deposition on the south side of the pier with corresponding erosion on the north side of the pier, similar to a groin. This is in agreement with the average wave angle during June 2005, which is less than 0 indicating incident waves from the southeast that drive alongshore transport towards the north. This process is also illustrated in Figure 6B. Figures 6D, 6E, and 6F depict a similar pattern, but the direction of net alongshore drift is reversed with deposition on the north side of the pier and erosion on the south side of the pier. The average wave angle from July 2005 until the end of the simulation period is greater than 0 , indicating incident waves from the northeast that produce a net alongshore transport towards the south.

GenCade tends to respond to changes in wave direction to produce local perturbations in the shoreline contour that are consistent with the presence of a coastal structure that disrupts the longshore flux producing the deposition/erosion pattern seen in the model results. The data do not show a change as sharp as an adjustment due to changes in incident wave direction. The measured shoreline position depicted in Figures $6 \mathrm{~B}$ and $6 \mathrm{C}$ does indicate a net shoreline retreat north of the pier, which is consistent with the model results. However, the measured shoreline adjustment is dispersed over a larger stretch of the beach without the abrupt change in the immediate vicinity of the pier as predicted by the model. Figures $6 \mathrm{E}$ and $6 \mathrm{~F}$ depict a reversal in net alongshore drift with a corresponding seaward shift of the modeled shoreline north of the pier and retreat south of the pier. The measured shoreline response is less obvious, but the shoreline north of the pier does show a net seaward shift. There is no obvious indication of shoreline retreat south of the pier. Overall, the shoreline position in the vicinity of the pier shows some response to changes in the alongshore drift, but the degree of response is much less pronounced compared to the model. 

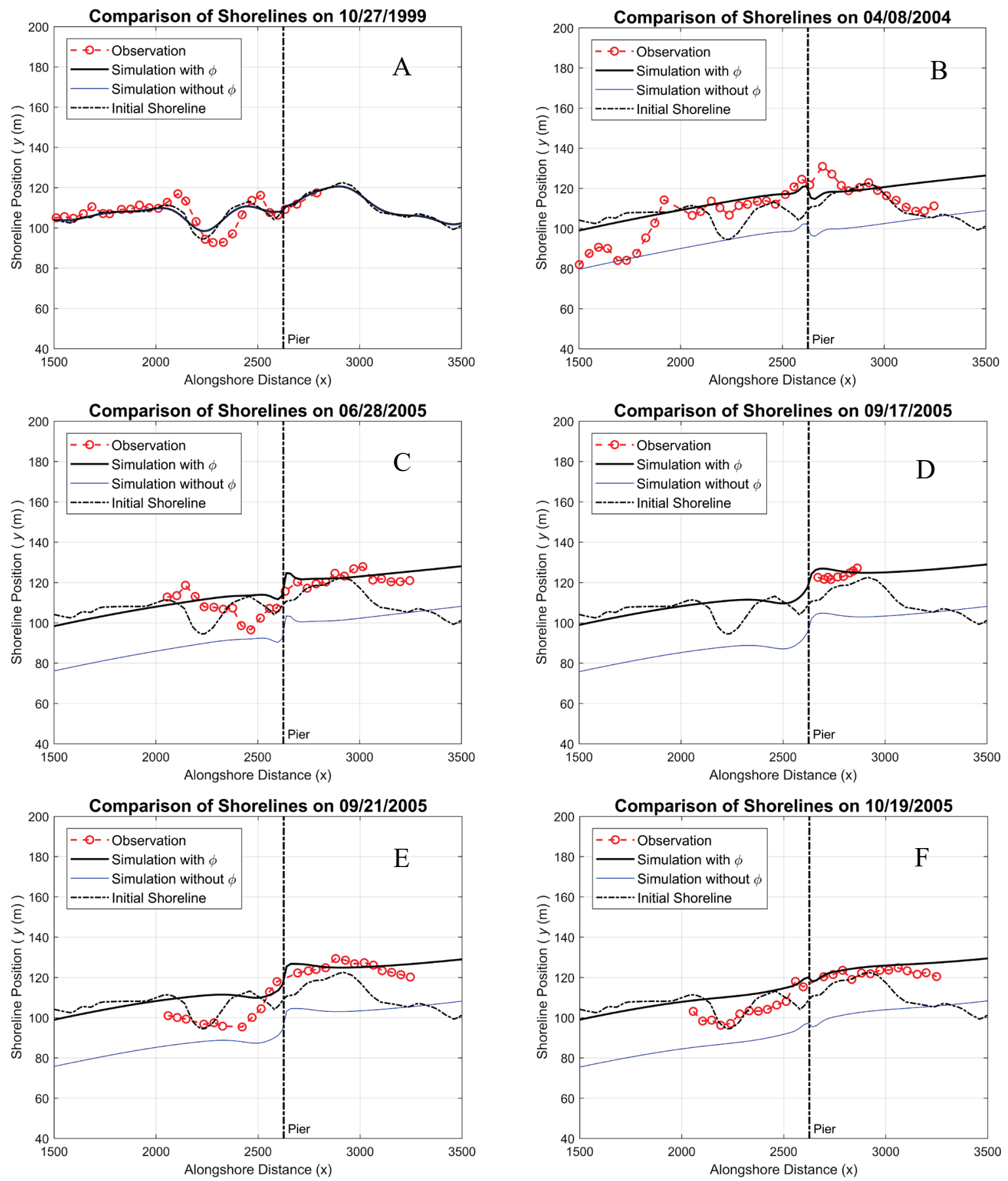

Figure 6. Comparisons of computed shoreline positions with observations at selected time periods. The first plot (A) depicts shoreline position shortly after the start of the simulation $(10 / 23 / 1999)$ and $(B)$ to $(F)$ advances through time. 
For model skill assessment, error statistics are computed based on the modeled and measured shoreline positions at cross-shore survey profiles at a given time (Table 2). RMSE is a measure of the deviation between model and measured shoreline position. The Scatter Index (SI) is the ratio of the standard deviation of the observation-to-prediction discrepancies to the average observation values (Hanson et al. 2009), i.e.,

$$
\mathrm{SI}=\frac{\sqrt{\frac{1}{\mathrm{~N}} \sum_{i=1}^{N}\left(E_{i}-\bar{E}\right)^{2}}}{\frac{1}{\mathrm{~N}} \sum_{i=1}^{N}\left|O_{i}\right|}
$$

where $N=$ number of observations, $E_{i}=m_{i}-O_{i}$ denotes the error between the modeled time series and measured data, $\mathrm{m}$ is a set of model simulation values, $\mathrm{O}$ is a set of observation values or known values as $\mathrm{O}$, the average error is $\overline{\mathrm{E}}=(1 / N) \sum_{\mathrm{i}=1}^{\mathrm{N}}\left|\mathrm{O}_{\mathrm{i}}-\mathrm{m}_{\mathrm{i}}\right|$, overbar is mean of the dataset. The normalized bias (NB) is defined as

$$
\mathrm{NB}=\frac{\frac{1}{\mathrm{~N}} \sum_{i=1}^{N} E_{i}}{\frac{1}{\mathrm{~N}} \sum_{i=1}^{N}\left|O_{i}\right|}
$$

which provides a trend of over-predicted model results if NB is positive or under-prediction if NB is negative.

Table 2 lists the values of the model skill parameters (i.e., RMSE, SI, and NB), the dates of the surveys, and the total number of transects for each survey, for the simulation with the inclusion of cross-shore transport (Figure 6). This table only lists 24 surveys during the period from 1999 to 2005, which provide more valid transect data for extracting shoreline positions. For the error, statistics were completed for all the transects at one survey, the values of the model skill parameters are the error measures for simulation shoreline profiles. For example, for the shoreline profile computed on 10/19/2005 with cross-shore transport, as shown in Figure 6F, the RMSE value of this computed shoreline profile is $6.843 \mathrm{~m}$, the SI value is 0.035 , and the NB value is 0.049 . By comparing all the measured shoreline position data, a total of 863 measured data, from all the surveys between 10/23/1999 and 10/19/2005, the RMSE value is $9.288 \mathrm{~m}$. As the observation data show the maximum shoreline advance relative to the initial shoreline position on 10/23/1999 is $45.573 \mathrm{~m}$ on $04 / 14 / 2003$, and the relative maximum retreat is $20.924 \mathrm{~m}$ on $10 / 12 / 2001$, then the maximum range of shoreline variations is $66.500 \mathrm{~m}$ (from -20.924 to +45.573 ). Thus, the total RMSE error $(9.288 \mathrm{~m})$ is $14.0 \%$ of the maximum range of shoreline changes in the Duck coast. The maximum relative RMSE in all the survey times (Table 2) is $22.8 \%$ on $8 / 8 / 2003$, and the minimum relative RMSE is $5.2 \%$ on $9 / 17 / 2005$. In terms of the relative RMSE, the simulation results by GenCade with the cross-shore transport are reasonably good. By comparing the total RMSE without cross-shore transport included (the value is $18.700 \mathrm{~m}$ ), the new capability for estimation of cross-shore transport significantly improved GenCade's predictability.

Figure 7 shows the statistics comparing with and without cross-shore transport. The horizontal axis (i.e., number of observations) denotes the statistical estimate based on selected 24 surveys 
from the 38 LARC surveys during the simulation time period (1999-2005). The dates of the 24 survey and statistical errors are given in Table 2. As shown in Figure 7A, the RMSE is consistently smaller with cross-shore transport than without it. The deviation increases until the 9th observation on 08/08/2003 when the modeled shoreline begins to align closer with observations. The SI (Figure 7B), as an indication of the variability from the mean, is smaller with cross-shore transport. The normalized bias NB (Figure 7C) indicates that the model tends to over- or underestimate the measured shoreline position. Without cross-shore transport, the model shoreline is negatively biased indicating the modeled shoreline position has underestimated from the measured shoreline position. The bias is smaller when cross-shore transport is included than without.

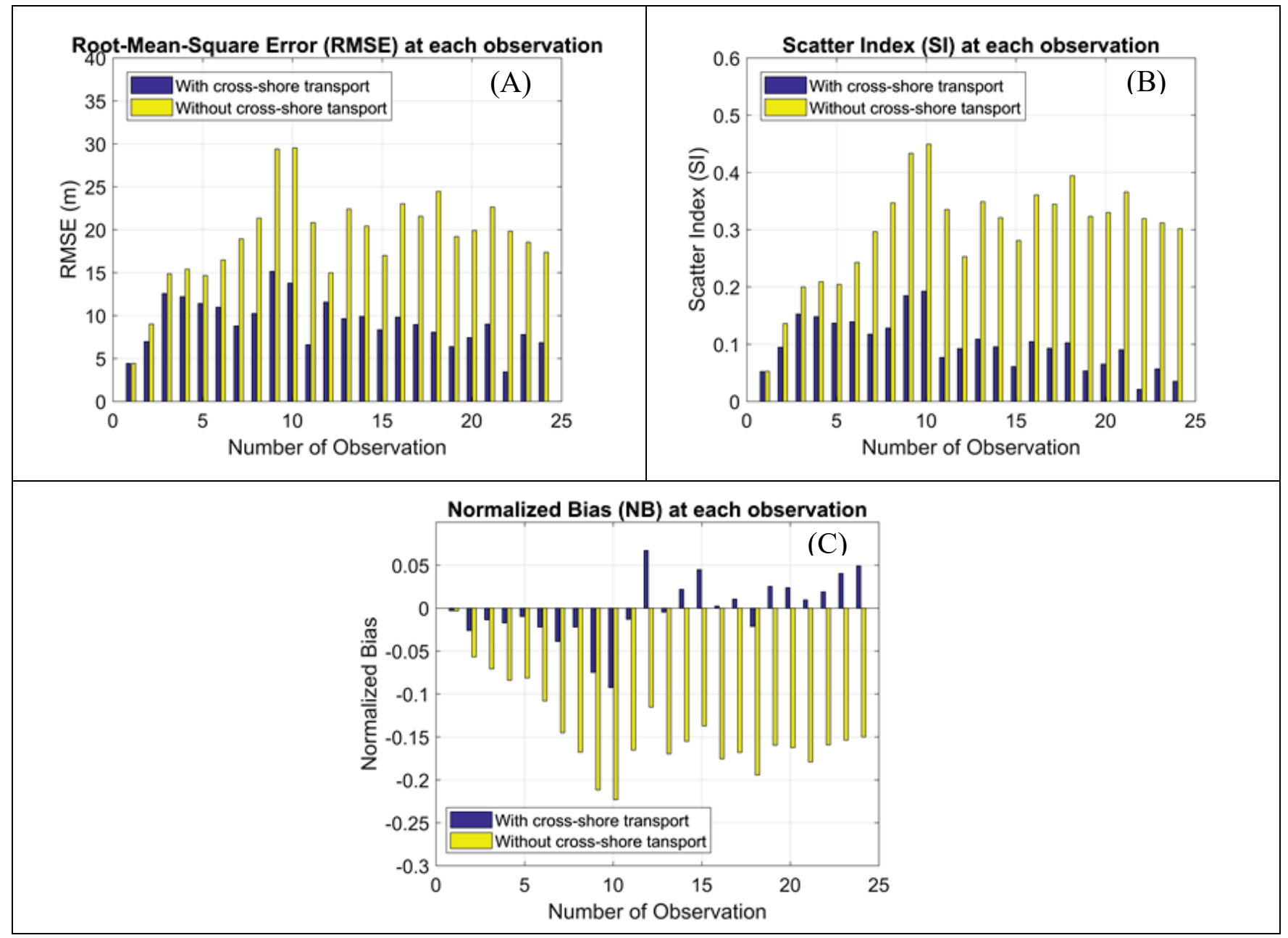

Figure 7. Model error statistics including (A) RMSE, (B) SI, and (C) NB during the 6 years from 1999 to 2005. 


\begin{tabular}{|c|c|c|c|c|c|}
\hline No. of Observation & Date & $\begin{array}{c}\text { Number of } \\
\text { Transect }\end{array}$ & RMSE (m) & SI & NB \\
\hline 1 & 10/27/1999 & 33 & 4.433 & 0.052 & -0.003 \\
\hline 2 & $10 / 05 / 2000$ & 27 & 6.966 & 0.095 & -0.026 \\
\hline 3 & $05 / 02 / 2001$ & 37 & 12.572 & 0.153 & -0.014 \\
\hline 4 & 08/08/2001 & 27 & 12.207 & 0.148 & -0.017 \\
\hline 5 & $10 / 12 / 2001$ & 27 & 11.424 & 0.137 & -0.010 \\
\hline 6 & $03 / 01 / 2002$ & 27 & 10.979 & 0.139 & -0.022 \\
\hline 7 & $08 / 14 / 2002$ & 28 & 8.803 & 0.117 & -0.039 \\
\hline 8 & $04 / 14 / 2003$ & 46 & 10.234 & 0.128 & -0.022 \\
\hline 9 & $08 / 08 / 2003$ & 27 & 15.147 & 0.185 & -0.075 \\
\hline 10 & $09 / 21 / 2003$ & 27 & 13.781 & 0.193 & -0.092 \\
\hline 11 & $01 / 08 / 2004$ & 27 & 6.608 & 0.077 & -0.013 \\
\hline 12 & $04 / 08 / 2004$ & 45 & 11.572 & 0.092 & 0.067 \\
\hline 13 & $07 / 19 / 2004$ & 25 & 9.641 & 0.109 & -0.005 \\
\hline 14 & $09 / 29 / 2004$ & 27 & 9.891 & 0.096 & 0.022 \\
\hline 15 & $11 / 22 / 2004$ & 26 & 8.348 & 0.061 & 0.045 \\
\hline 16 & $01 / 26 / 2005$ & 27 & 9.809 & 0.104 & 0.002 \\
\hline 17 & $03 / 16 / 2005$ & 27 & 8.956 & 0.093 & 0.011 \\
\hline 18 & $04 / 20 / 2005$ & 23 & 8.062 & 0.103 & -0.021 \\
\hline 19 & $06 / 28 / 2005$ & 27 & 6.385 & 0.053 & 0.025 \\
\hline 20 & $07 / 19 / 2005$ & 27 & 7.433 & 0.065 & 0.024 \\
\hline 21 & 09/01/2005 & 25 & 9.015 & 0.090 & 0.009 \\
\hline 22 & $09 / 17 / 2005$ & 9 & 3.448 & 0.021 & 0.019 \\
\hline 23 & $09 / 21 / 2005$ & 24 & 7.793 & 0.057 & 0.040 \\
\hline 24 & $10 / 19 / 2005$ & 26 & 6.843 & 0.035 & 0.049 \\
\hline
\end{tabular}

SUMMARY: This technical note presents a new cross-shore sediment transport formulation that has been implemented into GenCade, the USACE shoreline evolution simulation model. This formulation is developed by including nonlinear wave dynamics and sediment transport process in nearshore, driven by particle velocity, mean current (undertow and tidal current), and gravity (i.e., slope effect). By using asymmetrical near-bed orbital velocities derived by Abreu et al. (2010) and Ruessink et al. (2012), calculation of cross-shore transport is related to wave nonlinearity parameters such as the Ursell number, velocity skewness, and asymmetry of waves.

Validation of this new capability of GenCade was achieved by simulating shoreline changes in a $5 \mathrm{~km}$ long shoreline in FRF, Duck, NC, over a 6-year period from 1999 to 2005. Careful assessment of GenCade model skill was done by calculating model errors measured by skill parameters such as RMSE, SI, and NB. The GenCade simulations with cross-shore transport provide consistent reductions of errors in comparison to the control run (without cross-shore transport). Preliminary model validation shows that the new capability for estimation of crossshore transport significantly improved GenCade's predictability in shoreline changes.

Predicted spatiotemporal variations of cross-shore sediment transport in the FRF coastline reflect different sand movements in on- and offshore directions associated with fair weather (small wave) conditions and storms (large waves). However, estimated cross-shore transport rate needs to be further verified by using observation data (if available) or a cross-shore profile model. Undertow 
current and gravity effect play important roles in cross-shore transport process. Further investigation on formulations of currents (undertow and tidal current) and diffusive effect of gravity is needed.

ADDITIONAL INFORMATION: This CHETN was prepared as part of the USACE Coastal Inlets Research Program (CIRP) by Yan Ding, Richard Styles, Sung-Chan Kim, Rusty Permenter, and Ashley Frey, US Army Engineer Research and Development Center (ERDC), Coastal and Hydraulics Laboratory (CHL), Vicksburg, MS. Questions pertaining to this CHETN may be directed to Yan Ding (Yan.Ding@usace.army.mil) or the USACE CIRP Program Manager, Tanya M. Beck (Tanya.M.Beck@usace.army.mil). Additional information regarding CIRP may be obtained from the CIRP web site http://cirp.usace.army.mil/. Special thanks go to Lihwa Lin and Mary Bryant for their valuable review comments.

This ERDC/CHL CHETN-IV-123 should be cited as follows:

Ding, Y., R. Styles, S. C. Kim, R. Permenter, and A. Frey. 2020. Cross-Shore Transport Feature for GenCade. ERDC/CHL CHETN-IV-123. Vicksburg, MS: US Army Engineer Research and Development Center. http://dx.doi.org/10.21079/11681/35893

\section{REFERENCES}

Abreu, T., P. A. Silva, F. Sancho, and A. Temperville. 2010. "Analytical Approximate Wave Form for Asymmetric Waves." Coastal Engineering 57(7): 656-667.

Birkemeier, W. A., and E. B. Thornton. 1994. The DUCK94 Nearshore Field Experiment, Proceedings of the Conference on Coastal Dynamics '94, 815-821. New York, NY: American Society of Civil Engineers.

Bruun, P. 1962. "Sea-Level Rise as a Cause of Shore Erosion.” J. Waterway. Harbours Div. 88(1): 117-130.

Ding, Y., S.-C. Kim, A. E. Frey, R. L. Permenter, and R. Styles. 2018. "Probabilistic Modeling of Long-Term Shoreline Changes in Response to Sea Level Rise and Waves." Scour and Erosion IX: Proceedings of the 9th International Conference on Scour and Erosion. Edited by K.-C. Yeh, 203-211. London: Taylor \& Francis Group.

Elgar, S., E. L. Gallagher, and R. T. Guza. 2001. "Nearshore Sandbar Migration.” J. Geophys. Res. 106(C6): 1162311628.

Fernández-Mora, A., D. Calvete, A. Falqués, and H. E. de Swart. 2015. "Onshore Sandbar Migration in the Surf Zone: New Insights into the Wave-Induced Sediment Transport Mechanisms." Geo. Phys. Res. Ltrs. 42(8): $2869-2877$.

Forte, M. F., W. A. Birkemeier, and J. R. Mitchell. 2017. Nearshore Survey System Evaluation. ERDC/CHL TR-1719. Vicksburg, MS: US Army Engineer Research and Development Center.

Frey, A. E., K. J. Connell, H. Hanson, M. Larson, R. C. Thomas, S. Munger, and A. Zundel. 2012. GenCade Version 1 Model Theory and User's Guide. ERDC/CHL TR-12-25. Vicksburg, MS: US Army Engineer Research and Development Center.

FRF (Field Research Facility). 2019. FRF $8 m$ Linear Array Directional Waves. http://www.frf.usace.army.mil/dksrv/dk94/frf/FRF8m.html

Gallagher, E. L., S. Elgar, and R. T. Guza. 1998. “Observations of Sand Bar Evolution on a Natural Beach.” J. Geophys. Res. 103(C2): 3203-3215.

Hanson, J. L., B. A. Tracy, H. L. Tolman, and R. D. Scott. 2009. "Pacific Hindcast Performance of Three Numerical Wave Models.” J. Atmos. Oceanic Technol. 26(8): 1614-1633. 
Hoefel, F., and S. Elgar. 2003. "Wave-Induced Sediment Transport and Sandbar Migration.” Science 299(5614): $1885-1887$.

Hsu, T.-J., S. Elgar, and R. T. Guza. 2006. "Wave-Induced Sediment Transport and Onshore Sandbar Migration.” Coastal Eng. 53(10): 817-824.

Johnson, B. D., N. Kobayashi, and M. Gravens. 2012. Cross-shore Numerical Model CSHORE for Waves, Currents, Sediment Transport, and Beach Profile Evolution. ERDC/CHL TR-12-22. Vicksburg, MS: US Army Engineer Research and Development Center.

Kobayashi, N., M. Buck, A. Payo, and B. D. Johnson. 2009. "Berm and Dune Erosion during a Storm.” Journal of Waterway, Port, Coastal, and Ocean Engineering 135(1): 1-10. https://doi.org/10.1061/(ASCE)0733950X(2009)135:1(1)

Kobayashi, N., A. Payo, and L. Schmied. 2008. "Cross-Shore Suspended Sand and Bed Load Transport on Beaches.” J. Geophys. Res. 113(C7): C07001. doi:10.1029/2007JC004203

Kobayashi, N., A. Farhadzadeh, J. Melby, B. D. Johnson, and M. Gravens. 2010. "Wave Overtopping of Levees and Overwash of Dunes." Journal of Coastal Research 26(5): 888-900.

Komar, P. D. 1998 Beach Processes and Sedimentation. $2^{\text {nd }}$ Edition. New Jersey: Prentice Hall.

Kuriyama, Y., and T. Nakatsukasa. 2000. "A One-Dimensional Model for Undertow and Longshore Current on a Barred Beach." Coastal Eng. 40(1): 39-58.

Larson, M., and N. Kraus. 1989. SBEACH: Numerical Model for Simulating Storm-Induced Beach Change. Report 1-Empirical Foundation and Model Development. CACR-89-9. USAEWES, Coastal Engineering Research Center.

Malarkey, J., and A. G. Davies. 2012. "Free-Stream Velocity Descriptions under Waves with Skewness and Asymmetry." Coastal Engineering 68(October 2012): 78-95.

Rocha, M. V. L., H. Michallet, and P. A. Silvab. 2017. "Improving the Parameterization of Wave Nonlinearities The Importance of Wave Steepness, Spectral Bandwidth and Beach Slope." Coastal Engineering 121(March 2017): 77-89.

Rosati, J. D., R. G. Dean, and T. L. Walton. 2013. "The Modified Bruun Rule Extended for Landward Transport." Mar. Geol. 340(1): 71-81.

Ruessink, B. G., G. Ramaekers, and L. C. van Rijn. 2012.” On the Parameterization of the Free-Stream Non-Linear Wave Orbital Motion in Nearshore Morphodynamic Models." Coastal Engineering 65(7): 56-63.

Thornton, E., R. Humiston, and W. Birkemeier. 1996. "Bar-Trough Generation on a Natural Beach.” J. Geophys. Res. 101(C5): 12097-12110.

NOTE: The contents of this technical note are not to be used for advertising, publication,

or promotional purposes. Citation of trade names does not constitute an official endorsement or approval of the use of such products. 